\title{
Repeated Chest Computed Tomography Revealed Early-stage Miliary Tuberculosis
}

\author{
Hideo Okuno, Hideharu Hagiya, Shigeto Hamaguchi and Kazunori Tomono
}

Key words: miliary tuberculosis, computed tomography, immunocompromised

(Intern Med 59: 461-462, 2020)

(DOI: 10.2169/internalmedicine.3121-19)

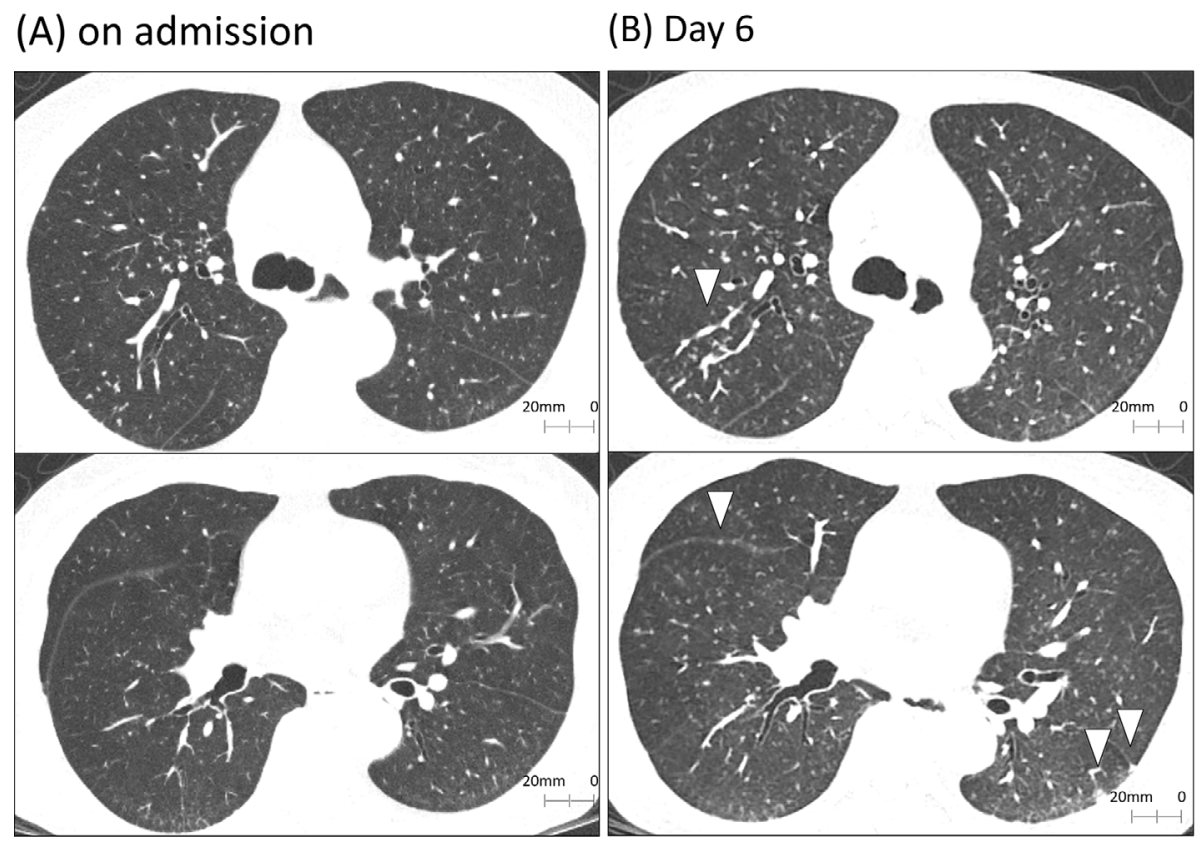

Picture.

A 71-year-old woman with polymyositis who had been treated with oral prednisolone (15 $\mathrm{mg} /$ day on admission) for 12 years was hospitalized due to a high fever. Chest computed tomography (CT) on admission revealed a left cervical abscess and centrilobular lung nodules suspected of being an intrabronchial infection (Picture A). Since intravenous administration of ceftriaxone did not improve her symptoms, chest CT was repeatedly performed on day 6 to follow the abscess, and randomly distributed small nodules, including pleural lesions, were detected (Picture B, arrowheads). Mycobacterium tuberculosis was identified from blood as well as sputum samples, leading to a final diagnosis of miliary tuberculosis with pulmonary tuberculosis. We did not find any nosocomial infection with delayed airborne precaution.
In this case, repeated CT successfully revealed the development of early-stage miliary tuberculosis; centrilobular lung nodules progressed to a miliary pattern within one week. Previous studies have indicated difficulties in obtaining an imaging-based diagnosis of miliary tuberculosis $(1,2)$. This case highlights the importance of performing CT repeatedly to diagnose miliary tuberculosis, especially among immunocompromised patients with infectious disease that do not respond to non-anti-tuberculosis antibiotics.

The authors state that they have no Conflict of Interest (COI). 


\section{References}

1. Kwong JS, Carignan S, Kang EY, Müller NL, FitzGerald JM. Miliary tuberculosis. Diagnostic accuracy of chest radiography. Chest 110: 339-342, 1996.

2. Bottiger LE, Nordenstam HH, Wester PO. Disseminated tuberculo- sis as a cause of fever of obscure origin. Lancet 1: 19-20, 1962.

The Internal Medicine is an Open Access journal distributed under the Creative Commons Attribution-NonCommercial-NoDerivatives 4.0 International License. To view the details of this license, please visit (https://creativecommons.org/licenses/ by-nc-nd/4.0/).

(C) 2020 The Japanese Society of Internal Medicine Intern Med 59: 461-462, 2020 